\title{
CURRENT MANAGEMENT FOR WORD FINDING DIFFICULTIES BY SPEECH-LANGUAGE THERAPISTS IN SOUTH AFRICAN REMEDIAL SCHOOLS
}

\author{
Ingrid de Rauville, Sandhya Chetty and Jenny Pahl
}

University of Kwazulu-Natal

\begin{abstract}
Word finding difficulties frequently found in learners with language learning difficulties (Casby, 1992) are an integral part of SpeechLanguage Therapists' management role when working with learning disabled children. This study investigated current management for word finding difficulties by 70 Speech-Language Therapists in South African remedial schools. A descriptive survey design using a quantitative and qualitative approach was used. A questionnaire and follow-up focus group discussion were used to collect data. Results highlighted the use of the Renfrew Word Finding Scale (Renfrew, 1972, 1995) as the most frequently used formal assessment tool. Language sample analysis and discourse analysis were the most frequently used informal assessment procedures. Formal intervention programmes were generally not used. Phonetic, phonemic or phonological cueing were the most frequently used therapeutic strategies. The authors note strengths and raise concerns about current management for word finding difficulties in South African remedial schools, particularly in terms of bilingualism. Opportunities are highlighted regarding the development of assessment and intervention measures relevant to the diverse learning disabled population in South Africa.
\end{abstract}

Key words: word finding difficulties, learning disabled children, assessment, intervention.

\section{INTRODUCTION}

Learners with language learning disabilities frequently experience word finding difficulties (Casby, 1992; German, 1998) as cited by German, 2005) Word finding difficulties (WFDs) are an integral aspect of the Speech-Language Therapist's management practices when working with a learner who has a language learning disability (LLD). Using The Royal College of Speech Therapists' definition of practice (1998), hereinafter, management refers to the assessment, formulating and implementing intervention programmes and decision making about discharge from therapy. Many factors impact on the complex management of developmental WFDs by South African Speech-Language Therapists (SLTs), including: controversies about the nature and impact of WFDs; the training of SLTs in WFDs; the role of the SLT in managing WFDs; the context in which services are provided; the model of service delivery in use; policy issues including inclusive education; outcomes based education and language issues. Furthermore, Speech-Language Therapists (SLTs) have experienced frustration with the outcome of therapy for WFDs (Haynes, 1993).

"Learning disability is a general term that refers to a heterogeneous group of disorders manifested by significant difficulties in the acquisition and use of listening, speaking, reading, writing, reasoning or mathematical abilities" (National Joint Committee on Learning Disabilities (1991, as cited by Owens, 2004). South African learners with learning disabilities exhibit discrepancies between their intellectual potential (usually average to above average) and expected academic performance and are typically admitted to remedial schools (S, Mohamed, personal communication, August, 24, 2004).Speech-language therapy services for learners with LLD and WFDs in the South African context are frequently provided in the context of remedial education. Within the current educational system in South Africa, learners with LLD (and possible WFDs) are educated at long and short-term remedial schools or within mainstream schools. SLTs' practice in different educational settings is shaped and influenced by current and changing educational policies such as Outcomes Based Education (Department of Education, 2001). Another policy influencing the practice of SLTs is inclusive education where the focus is on overcoming barriers in the system that prevent meeting learning needs by adapting the support systems in the classroom (Department of Education, 2001). Policies like this impact on service delivery models for learners with LLD and possible WFDs viz. individual versus group therapy, traditional pull-out system or classroom-based therapy.

WFDs in children with LD, who meet the criteria for admission into a remedial school, are pervasive in nature, and impact on their communicative and academic performance (Faust, Dimitrovsky \& Shacht, 2003; Lemer, 2000). This takes the form of difficulties with confrontation naming, reading, and conversational discourse. Secondary behaviours such as hesitations, repetitions and re-formulations occur (Dockrell, Messer, George \& Wilson, 1998 ) and may result in inaccurate messages being conveyed (Faust et al., 2003). It is therefore important for WFDs to be systematically identified, assessed and treated as early as possible in the learner's educational career (Faust et al., 2003). Speechlanguage therapy interventions for WFDs have been reported to be ineffective (Dockrell et al., 1998), and have thus not enabled the learner to achieve the academic and communicative competence required for progress in education.

\section{The causes of Word Finding Difficulties}

There is no unequivocal explanation for the presence of WFDs (Casby, 1992). Within a psycholinguistic framework, limited processing resources, inadequate or ill-defined semantic representations, inadequate phonological specifications and naming speed deficits are possible contributing causes of WFDs (Dockrell et al., 1998).

Within the processing view, the two inter-related components of the initial learning, organisation and storage of information that impacts on the learning of vocabulary (Easton, Sheach \& Easton, 1997), and the ability to retrieve words (Macgregor \& Leonard, 1989, cited in Easton et al., 1997) may impact on WFDs. Thus storage strength (i.e. how well a word is learned) and retrieval strength (i.e. how easily a word is retrieved) are important. A debate exists about the types of word-knowledge viz. semantic 
and phonological features of a word and the link between them in relation to storage and retrieval strength (Easton et al., 1997).

An additional view of the cause of WFDs is that of inadequate semantic specification (Easton et al., 1997). Semantic deficits result in simple semantic networks, with limited options for associations for stimulus words, which may result in oral and written WFDs (Casby, 1992).

A further causal view is that WFDs are attributable to an inadequate phonological representation (Easton et al., 1997). Inadequate phonological representation could, according to a processing model used by Chiat and Hunt (1993), indicate difficulty at an input (phonological representation) or output (phonological access) level. Naming difficulties may suggest difficulties in phonological storage (Webster, 1994). Deficits in phonological access may present as difficulties in the naming of familiar words such as colours, digits, letters or objects (Clark, 1988 as cited by Webster, 1994).

However while it is not always easy to determine what the underlying cause of the child's WFD is (Easton et al., 1997), it is important to assume an interaction between the two processes of semantic representation and phonological specification.

\section{Assessment for WFDs}

According to German (1989a), a comprehensive assessment for WFDs should incorporate naming tasks, a comprehension task and the identification of word finding characteristics. A thorough assessment of WFDs is needed for bilingual learners (German, 1989a), which is of particular importance in the South African context. Learners acquiring English as a second language, particularly in the school setting, should have their abilities assessed using tools sensitive to their cultural and linguistic backgrounds (Cheng, 1994; Montgomery, 1999 as cited by Apel, 2001).

The strategies for assessing WFDs may be formal and informal (Wiig \& Semel, 1984). Spontaneous language sample analysis is an informal tool suggested by Wiig and Semel (1984). A number of formal or standardised assessment procedures of British and American origin used by SLTs to assess word finding are highlighted in available literature, but may be of limited application to the South African learner. Wiig and Semel's (1984) guidelines for selection of procedures for assessing WFDs highlights the need to have a range of assessment contexts and procedures to diagnose or to determine the nature, severity and impact of a WFD.

To provide an in-depth assessment of word finding abilities and difficulties, one has to select multiple procedures with a number of tasks which require naming in a variety of contexts (Wiig \& Semel, 1984), such as:

- Rapid naming upon confrontation of visual stimuli (such as the Renfrew Word Finding Scale ${ }^{1}$ Renfrew, 1972, 1995).

Rapid naming of automatic sequential series (such as the familiar sequences criterion referenced sub-test of the Clinical Evaluation of Language Fundamentals-Four, Semel, Wiig \& Secord, 2003).

Rapid automatised naming (such as the rapid automatic naming task of the Clinical Evaluation of Language Fundamentals-Four, Semel, Wiig and Secord, 2003).

Rapid naming of words in free or controlled association tasks.

The RWFS as a standardised test name is used to represent both the old version of the test (Renfrew, 1972) and the new version of the test (Renfrew, 1995), which has altered its name to the Word Finding Vocabulary Test (WFVT). This differentiation was not made on the questionnaire.
German and Simon (1991), also highlight the importance of assessing children's WFDs in discourse.

While a battery of reliable and valid measures, which allow for the profiling of WFDs, is important, the limitations of formal assessment tools applied to the South African context need to be acknowledged. Furthermore, a shift from standardised testing to criterion-referenced and educator-produced tests is recommended (Department of Education Directorate: Inclusive Education, 2002)

\section{Intervention}

Word finding intervention is complex with no single treatment approach available that is known to address all WFDs. For storage difficulties, therapy should identify and elaborate semantic features of words. For retrieval difficulties, therapy should aim at semantic categorisation or visual imagery (Wiig \& Becker-Caplan, 1984 as cited in German, 1992). When working with storage, one should aim to increase vocabulary, targeting common, frequent and meaningful words and those with concrete referents. The words should be taught in an orderly way, such as by using themes, and should highlight categorical and associative relationships (Nippold, 1992).

Aims of intervention for WFDs (Nippold, 1992) include hierarchically enhancing naming accuracy, improving retrieval strength and increasing the use of strategies by increasing metacognitive and meta-linguistic awareness of factors that affect word finding ability, such as looking at meaning changes across contexts (Nippold, 1992).

The focus of intervention differs if a learner presents with WFDs in spontaneous language or discourse. Therapy should focus on increasing accuracy and fluency rate. A number of retrieval strategies, such as phonological, visual and semantic categories in discourse, need to be used and taught (German, 1992). Response to particular types of intervention also informs us of the nature of the learner's problem in relation to reading difficulties. Learners with single phonological core deficits respond well to phonologically based therapy, which aims to increase phonemic awareness. Learners with single processing speed deficits or a double-deficit (a deficit in both areas) are typically only partially served by such intervention. They would require emphasis on building fluency in reading and building automaticity in lower level processes serving these skills (Wolf \& Segal, 1992).

From the above it is evident that working with learners with LLD and WFDs is a complex area, impacted on by factors such as changing educational policy. It is also an area where SLTs have experienced frustration with the outcome of therapy (Haynes, 1993).

Since WFDs are frequently found in learners with LLD (Casby, 1992) and are an integral part of the SLTs' management when working with LLD, the purpose of this study was to determine current management for WFDs in learners with LLD within the context of South African remedial schools, an undocumented area of investigation. Such investigation may highlight current strengths and difficulties in managing learners with WFDs and serve to guide SLTs toward the required shift in management within the South African educational setting. SLTs' opinions on the management of learners with LLD and WFDs'currently used in the various remedial educational institutions were important to ascertain how these management practices meet the current needs of therapists and learners. 
the questions were close-ended questions. The questions followed a Likert Scale format (Bailey, 1991). A statistical programme, Statistical Package for the Social Sciences (SPSS) (SPSS Inc., 1995), was used to explore patterns identified using frequency counts and percentages. Four open-ended questions were included in the questionnaire allowing for richer data to be obtained. The responses to the open-ended questions were qualitatively analysed. All questionnaires were coded using letters and numbers on questionnaires to ensure anonymity and confidentiality.

\section{Focus Group Discussion Schedule}

Information obtained from the questionnaire needed to be explored further to improve the quality and richness of the information obtained (McMillan \& Schumacher, 2000). This was achieved by developing a focus group discussion schedule which documented the open-ended questions to be investigated in an unstructured way (McMillan \& Schumacher, 2000) using questions to probe further information where necessary.

Participants in the focus group discussion were from Kwa-Zulu Natal which allowed ease of access. Eight participants attended the single focus group discussion at which the researcher and a scribe were present.

\section{Data analysis}

Data analysis for this research embodied both quantitative and qualitative analysis as the research tools used for data collection characterised both types of research. According to Vithal and Jansen (1997) data analysis includes three steps, summarised as (1) scanning and cleaning the data, (2) organizing the data and (3) representing the data.

These steps and how they were applied to this study are presented in Table 2.

\section{Table 2: Description of the 70 Participant SLTs}

\begin{tabular}{|l|l|}
\hline \multicolumn{1}{|c|}{ Parameter } & \multicolumn{1}{c|}{ Summarised description } \\
\hline $\begin{array}{l}\text { Years of } \\
\text { Experience }\end{array}$ & $\begin{array}{l}\text { 60\% of SLTs: 10 years or less experience } \\
17 \% \text { of SLTs: 11-20 years experience } \\
23 \% \text { of SLTs: 21 years + experience }\end{array}$ \\
$\begin{array}{l}\text { Number of Years } \\
\text { working with }\end{array}$ & Mean number of years: 7,24 years \\
\hline $\begin{array}{l}\text { University } \\
\text { Attended }\end{array}$ & $\begin{array}{l}\text { More than 80\% of SLTs attended the former } \\
\text { UDW,Wits or Pretoria }\end{array}$ \\
\hline $\begin{array}{l}\text { Language of } \\
\text { Therapy }\end{array}$ & $\begin{array}{l}\text { SLTs are guided by the language medium of the } \\
\text { school. The majority of SLTs at dual medium } \\
\text { schools provide therapy in English and Afrikaans. } \\
\text { SLTs at single medium schools provide therapy in } \\
\text { the language of the school }\end{array}$ \\
\hline
\end{tabular}

\section{Procedure}

The research procedure involved a number of pivotal phases. Each phase was dependant on the completion of the previous phase. A summary of the research procedure, highlighting the phases is presented in Figure 2.

\section{PHASE 1}

- A list of remedial schools in SA was obtained from SAUVSE.

- Permission from regional Superintendent Generals to perform the research was obtained.

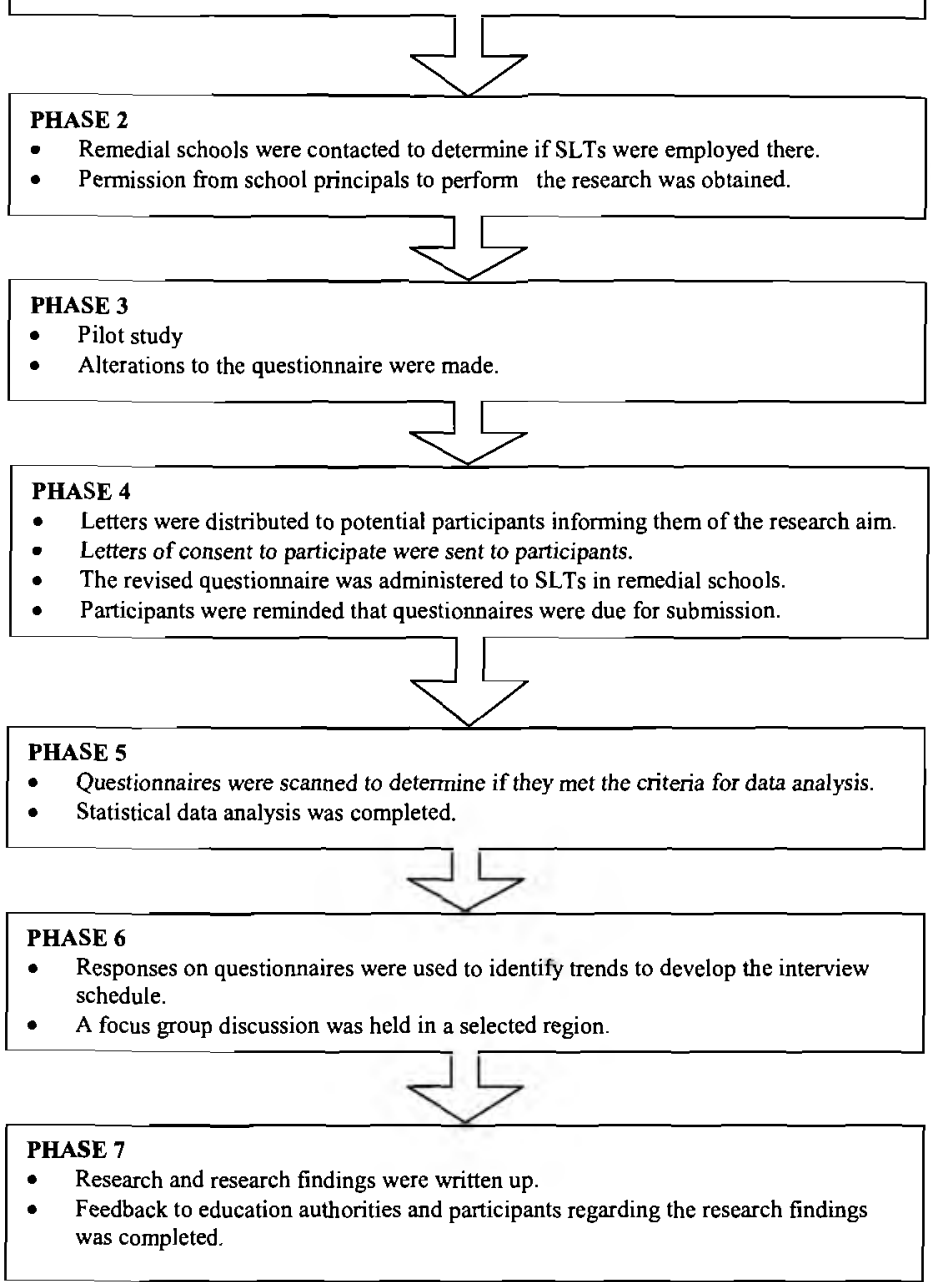

\section{Figure 2: Summary of Research Phases}

\section{Ethical considerations}

Using guidelines outlined by Leedy (1997) certain ethical issues were considered for this research study. Potential participants were informed in writing about the research study. Information included an ethical clearance number $(03140 \mathrm{~A})$, who was undertaking the research, why it was being undertaken and who financed it. A letter to possible participants included a consent form, (informed consent) indicating willingness to participate in the research. Letters to participants highlighted that they could withdraw from the study at any time, or refuse to participate without any penalty. Confidentiality in terms of the participants, both SLTs and remedial schools, was guaranteed. All the information recorded in this research document was coded in order to uphold this. Furthermore, the participants were assured that once the study was completed, audiocassettes used for the recording of the focus group discussions would be destroyed. Results of this study were provided to the participants. A summary of the findings and the implications thereof, were posted, faxed or e-mailed to the individuals, institutions, Superintendent Generals of the provinces and all the relevant school principals that participated.

\section{Reliability and validity}

For the purpose of this study, a pilot study was conducted to 
refine the questionnaire, with the aim of increasing reliability. Ecological validity was evaluated by the extent to which findings could be generalised beyond the findings of the present study (McMillan \& Schumacher, 2000). Strategies used to increase validity in the context of this research included varied data collection strategies (McMillan \& Schumacher, 2000) (for this study, a questionnaire and focus group discussion). This resulted in the triangulation of data across techniques, where consistency of findings by different data collection methods was checked (Bailey, 1991).

It was important to be aware of the Hawthorne effect, where participants may have acted differently since they were participants in a research project (McMillan \& Schumacher, 2000). Furthermore, acknowledging bias, particularly in descriptive research, was important since it is inevitable (Leedy, 1997). Disciplined subjectivity and inter-personal subjectivity assisted in acknowledging bias (McMillan \& Schumacher, 2000). Therefore, a daily field log was kept, a field journal written and ethical decisions recorded. Finally, it is important to highlight that what was being researched was "reported practice", i.e., what clinician's said they did was not necessarily what they may do in actual practice.

\section{RESULTS}

Results from the questionnaire, completed by 70 SLTs in South African remedial schools, and from the focus group discussion, involving SLTs in the greater Durban area in KwaZulu Natal follow. The results are presented and discussed in two main sections: assessment and intervention practice.

Current Assessment Practice, especially Procedures used for WFDs

\section{Assessment Procedures}

Results indicated that participant SLTs usually used both standardised and informal assessment procedures when assessing for WFDs (question 13). "Other" assessment procedures used by only $8 \%$ of participants, included subjective measures, speaking to parents and other members of staff and observation. A summary of results obtained is presented in Figure 3.

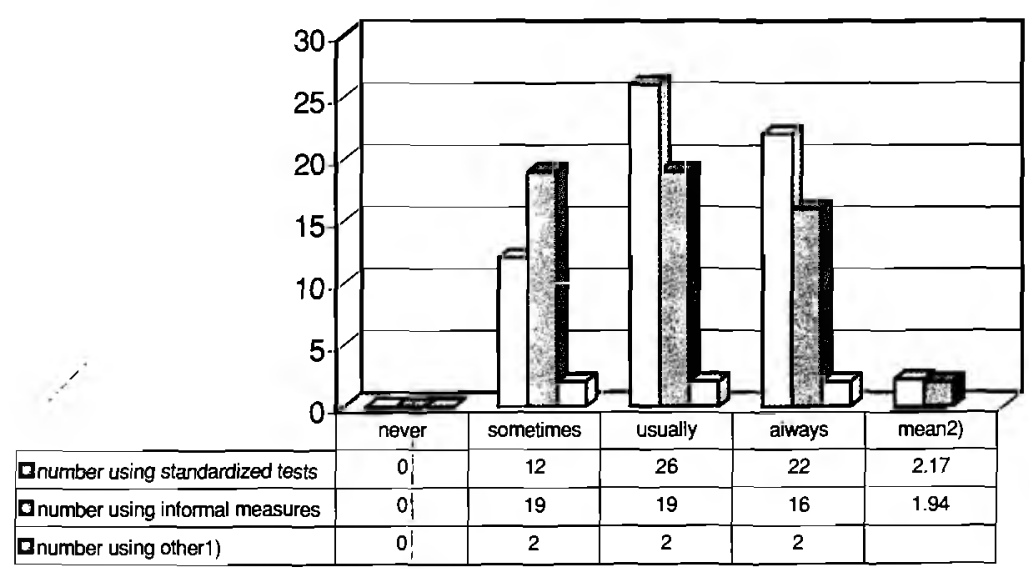

Figure 3: Assessment procedures used by participant SLTs for learners with LLD and WFDs ( $n=60)$

1. The measures listed under "other" include subjective measures, speaking to parents and other members of staff, observation and a combination of standardised tests and informal measures.

2. The calculation of the mean is based on allocating 0 for a "never" response, 1 for a "some times" response, 2 for a "usually" response and 3 for an "always" response.

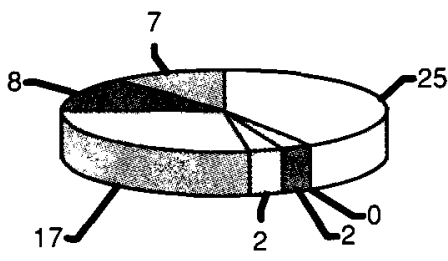

TOTAL NUMBER OF RESPONSES $=61$

\section{Standardised Assessments}

Participants were asked to indicate which standardised assessment tools they used in assessing WFDs in learners with LLD (question 14). It was found that the Renfrew Word Finding Scale (Renfrew, 1972 , 1995) was by far the most frequently used test to assess WFDs.

Eighty three percent of the participants who answered this question used either the Renfrew Word Finding Scale (RWFS) only or used it together with some other test(s). The results are summarized in Figure 4.

The use of the RWFS as a tool for assessing WFDs was further explored in the focus group discussion to determine participants' views of this tool for identifying WFDs. Participants at the focus group discussion offered views including that the RWFS depended on an intact vocabulary, identified only severe WFDs, needed to be used with another tool and did not effectively test for WFDs, as indicated by the following excerpt:

\section{“...I don't believe it's more effective than just even a spontaneous language sample charting the WFD...."}

Informal Measures Used In the Assess-

On the questionnaire, participants were asked to indicate which informal measures were used to identify WFDs (question 15). Language sample analysis (LSA) or discourse analysis (DA) was the most frequently used informal measure to identify WFDs. Thus $77 \%$ of the participants in the sample who answered the question used either LSA or DA only or together with some other measure(s). These results are summarised in Figure 5.

\section{SLTs View of Assessment Procedures for WFDs}

The results showed that $45 \%$ of participant SLTs in the sample disagreed that assessment procedures were relevant to the South African population but $58 \%$ agreed that the procedures assisted in identifying WFDs. Thirty four percent disagreed and $31 \%$ remained neutral regarding assessment procedures providing sufficient detail to provide treatment goals.

The results suggest that almost fifty percent of the participants working with WFDs in LLD were aware that the formal tools used were not relevant to the South African population. 


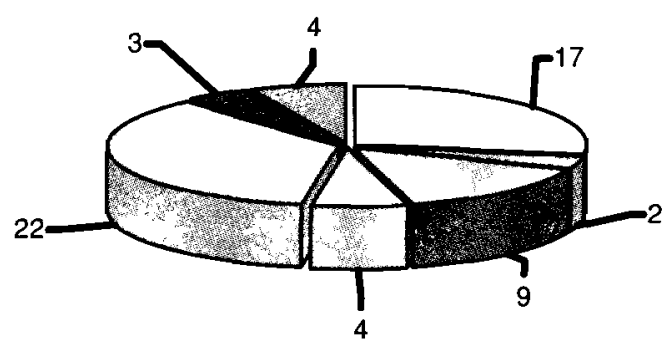

TOTAL NUMBER OF RESPONSES $=61$

Figure 5: Informal measures used for assessment of WFDs

(Key: LSA=language sample analysis. $\mathrm{DA}=$ discourse analysis)

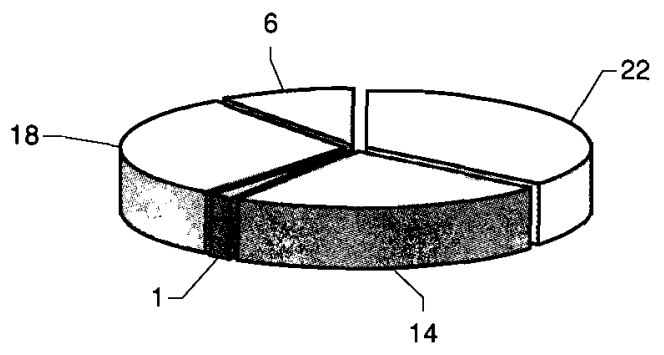

TOTAL NUMBER OF RESPONSES $=61$

Figure 6: Formal programmes used in intervention

(Key: LS= Lingui Systems)

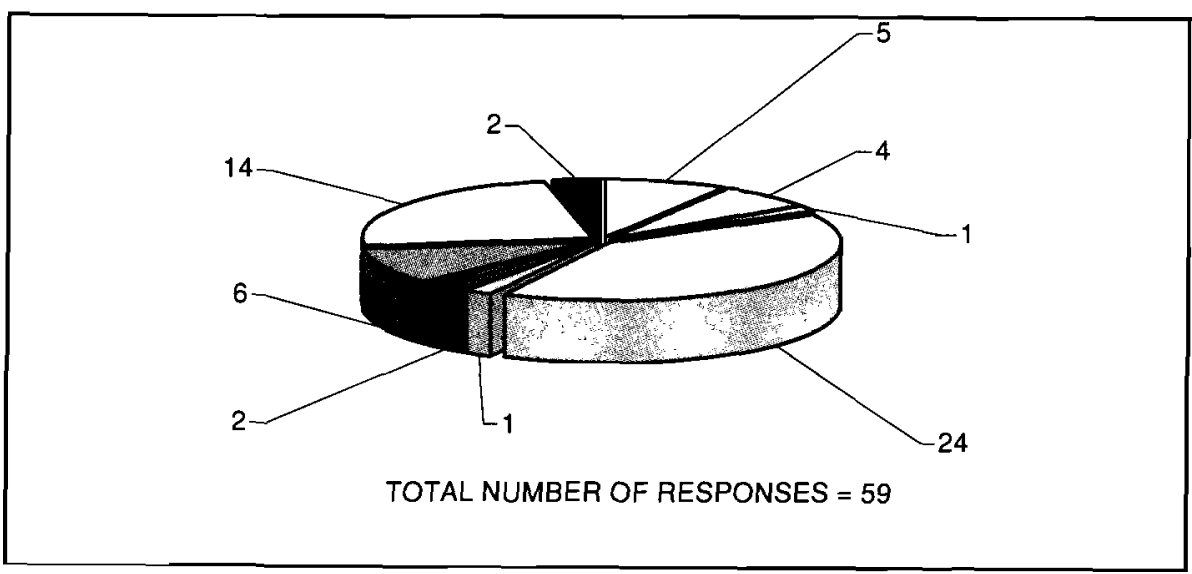

Figure 7: Therapeutic strategies used by participant SLTs in intervention for WFDs

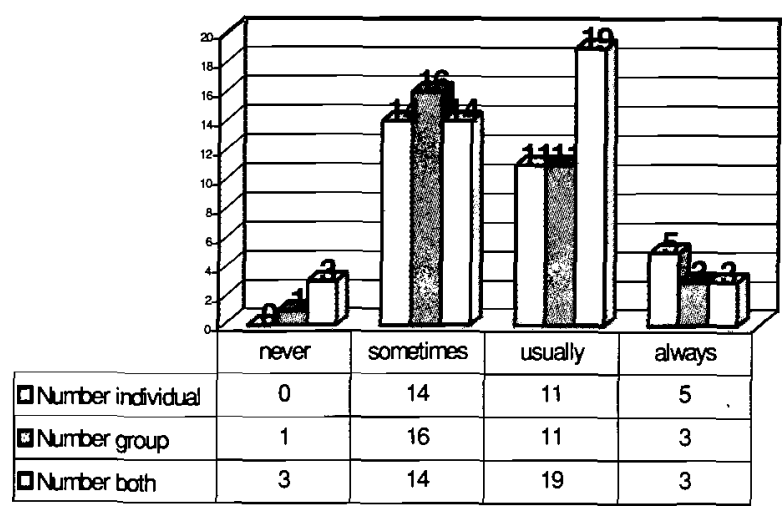

Figure 8: Number of participant SLTs who reported providing both individual and group therapy $(\mathbf{n}=59)$
Current Intervention Practice, especially Procedures Used for Learners with WFDs

The second area of focus was current management practice in terms of intervention procedures used for learners with LLD and WFDs (question 16). More than $60 \%$ of the participants in the sample did not use any formal intervention programme. Of those who did use a formal programme, a variety of programmes were given, with no particular one being used by the majority of schools in the sample. The results obtained are summarized in Figure 6.

The findings suggested that phonetic cueing combined with some "other" strategy was the informal therapeutic strategy most used in working with LLD children with WFDs (question 17). Ninety one percent of the participants who answered the question used either phonetic cueing only or together with some other strategy or strategies. Other informal strategies included for example: categorizing, associations, mind mapping, cloze tasks and visual cueing. A summary of the results indicating the therapeutic strategies used in intervention, is presented in Figure 7.

\section{Administering Therapy}

Participants provided either group, individual or both individual and group therapy to learners with LLDs and WFDs (question 10). A summary of results is presented in Figure 8.

Using the Chi Square Test of Association, no significant differences between the provision of individual versus group therapy, were noted. However, qualitatively, some differences were identified. This issue was explored during the focus group discussion and revealed the following about intervention for learners with WFDs. Three/variables were identified as influencing whether SLTs provided intervention for WFDs individually or in a group. These variables were the SLT's caseload, the population of learners at the school, and decisions of school management. Participants in the focus group discussion, indicated that the greater the caseload, the more likely group intervention was provided. Further, the more severe, a learner's difficulty the less likely they were to receive group therapy. In terms of caseload, two thirds of the participants in the sample saw 10 or $/$ less learners with LLD and WFDs per week. These results are summarized in Figure 9. 


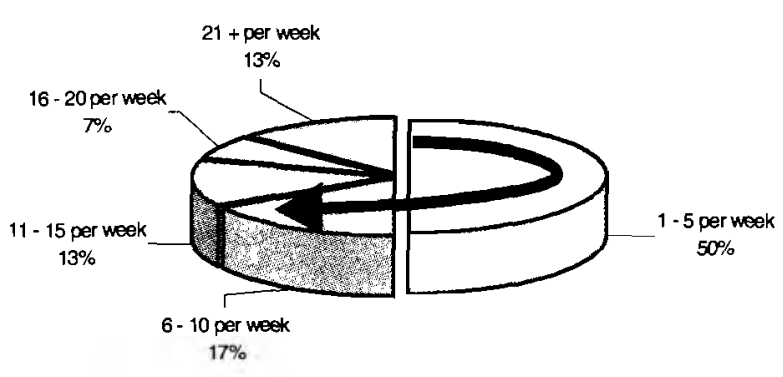

TOTAL NUMBER OF RESPONSES $=60$

Figure 9: Number of learners with learning disabilities as well as with WFDs seen per week

\section{SLT' Views on Intervention Procedures Used for WFDs}

An equal number of participants in the sample (36\%) agreed or were neutral in terms of intervention procedures being relevant to the South African population of learners with WFDs and LLDs (question 21). Sixty one percent of the participants agreed that intervention procedures were useful in addressing WFDs.

\section{Continuing Professional Development in the Area of WFDs}

There was an overwhelming response $(100 \%)$ where all participant SLTs in the sample wanted WFDs to be covered in continuing professional development programmes. Due to this overwhelming response, continuing professional development as an issue was further explored during the focus group discussion. The results are discussed in the discussion of current practice in terms of intervention procedures.

\section{DISCUSSION}

\section{Current Assessment Practice for WFDs in Learners with LLD}

An in-depth and thorough assessment for WFDs in learners with LLD with multiple procedures and a number of tasks in a variety of contexts is recommended (Wiig \& Semel 1984, Wolf \& Segal 1992, German, 1989a). Despite this, the RWFS as a single tool was by far the most frequently used standardised assessment tool for identifying WFDs. A number of possibilities for this assessment practice exist. These include training in WFDs, knowledge bases, available resources and policies. Knowledge from undergraduate training may be related to limited choice of assessment procedures for WFDs since two-thirds of participant SLTs responded that word finding was not an area covered in training. On the other hand, the availability of resources in the South African context could impact on the choice of assessment tools used. SLTs may be restricted in purchasing standardised procedures specifically for WFDs like the Test of Word-Finding (TWF) (German, 1989b) due to availability, high costs or other practical reasons. Standardised assessment tools are generally expensive. The RWFS is relatively cost effective. It is also quick to administer (Renfrew, 1995), making it functional for SLTs in the remedial school environment with large caseloads (Stockman, 2000).

In assessment, the literature stresses the importance of identifying the type and possible cause of the WFD. This influences the intervention selected. While some participant SLTs described WFDs according to semantic deficits, retrieval deficits and general characteristics of WFDs, the descriptions did not seem to match their assessment practices. These focussed mainly on assessing expressive vocabulary using the RWFS. The purpose of the RWFS is to identify if a child is able to name a word (Renfrew, 1995), not to assess word finding specifically. The use of the RWFS could therefore impact on service delivery, since it provides limited information about WFDs. In comparison German's Test of Word Finding (1989b), assesses accuracy of word finding, word comprehension, speed of naming, use of gestures and extra verbalizations. Augmenting assessment with qualitative observation of how the learner responds (as recommended by Renfrew, 1995), provides additional, valuable but partial information about WFDs. Furthermore, Renfrew (1995), when commenting on studies informing revisions to the RWFS test, notes that its use with a South African population is problematic (Pahl \& Kara, 1992). Using tests not standardised on the population with which you work impacts on the validity of findings (Apel, 1999). SLTs in South African remedial schools need to be aware of this limitation regarding the interpretation of formal test findings when assessing WFDs.

Using vocabulary tests, such as the RWFS, with multicultural populations often provides a negatively biased view of linguistic competence (Stockman, 2000). Using standardised tests not normed for our population highlights ethnocentricity. With the shift in South African educational policies, criterion-referenced and educator-produced tests are recommended by the Department of Education (Department of Education Directorate: Inclusive Education, 2002). Consistent with the Department of Education's recommendation for criterion-referenced tests, Terrell and Terrell (1993) suggest the use of criterion-referenced assessments with individuals from diverse cultural backgrounds. SLTs assessing WFDs should consider devising criterion- referenced and educator-produced tests for use in the context of South African remedial schooling.

The most frequently used informal assessment procedures for identifying WFDs in learners with LLD were language sample analysis (LSA) or discourse analysis. The use of LSA as an informal assessment procedure to determine how WFDs create difficulties for the learner with a LLD is recommended by Wiig and Semel (1984). Using LSA with the learner with LLD is particularly relevant when formal tests are not relevant to the population with whom we work (Pahl \& Kara, 1992). However, it is important to bear in mind whether the LSA is in the learner's first language. Apel (1999) suggests that SLTs use context- based assessment methods such as assessing communication skills in the classroom. Such an approach would be consistent with a more consultative or collaborative role (Schoeman, 2003).

Current Intervention Practice, especially Procedures Used for WFDs in Learners with LLD

The findings of the study revealed that most participant SLTs in the sample did not use formal programmes for intervention. This is consistent with the limited availability of specific programmes 
for WFDs (German, 1992). Possible reasons for predominant use of informal programmes are similar to those discussed under assessment for WFDs namely: knowledge of available programmes, limited training, and limited resources. It is possible that even if resources were not limited, intervention programmes developed in other countries using unfamiliar stimulus material would be inappropriate to South African leamers with WFDs. Using informal programmes may be an advantage in that SLTs can plan and develop appropriate interventions for the South African context.

Most participant SLTs agreed that the formal intervention procedures they used for WFDs in learners with LLD were useful. Although participant SLTs found the programmes useful, the programmes were not specifically developed for targeting WFDs. Therefore, a very specific aspect of WFDs, which may not be the learner's area of difficulty in word finding, may be addressed, raising questions about the effectiveness of intervention.

The most frequently used informal therapy strategy for WFDs was phonetic, phonemic or phonological cueing. These findings are supported by literature recommending these strategies for intervention with WFDs (Wiig \& Semel, 1984). However, SLTs need to be aware that response to a specific type of intervention informs us of the nature of the learner's problem. For example, if the response to phonological based therapy is good, the difficulty is phonologically based (Wolf \& Bowers, 2000). Adopting such an approach to treatment implies that diagnostic therapy is relevant for WFDs. Intervention strategies would need to change if the child does not respond to selected strategies. SLTs in remedial education in South Africa should also incorporate into intervention for WFDs a number of other skills. These include: phonological segmentation and imagery (Wing, 1990), self-cueing, semantic intervention and phonological awareness intervention (Wittmann, 1996), combined semantic and phonological treatment approaches (Easton et al., 1997) and discourse based intervention (Stiegler \& Hoffman, 2001). However, since there is little evidence to support the efficacy of treatment approaches for learners with WFDs (Casby, 1992), SLTs need to monitor the effects of their treatment (Wittmann, 1996). This will assist in determining the most appropriate treatment for the learner with LLD and WFDs.

The predominant languages in which intervention for WFDs was provided were English and Afrikaans. A concern arises for learners who speak other official languages of South Africa and for whom the language of instruction is English or Afrikaans. When working with learners who use more than one language, a differential diagnosis is necessary. The aim is to determine if the difficulties are related to a first language learning problem, a problem with acquiring a second language or if the learner is in a normal process of learning an additional language (Miller, 1984). SLTs should question which the optimal language to provide therapy for WFDs in, is (Miller, 1984).

Consistent with the findings of Haynes (1993), participant SLTs in South African remedial schools seem to be providing strategies for WFDs but it did not appear that consideration was given to the general aims of intervention outlined by German (1992). Since therapy for WFDs is complex and there is no single intervention approach that addresses all WFDs, the general aims of intervention as outlined by German (1992) can be used to guide such intervention. These aims are to enhance naming accuracy, improve retrieval strength and develop meta-cognitive and meta-linguistic strategies to improve WFDs and to increase accuracy and fluency in spontaneous language. Consistent with the findings of Haynes (1993), SLTs in South African remedial schools need to extend their understanding of language processing so that therapy for WFDs can be addressed in a broader manner. The issues raised by participants about institutions' demands and experience for example, become secondary to providing the most effective and accountable service (Baum, 1998), for learners in remedial schools.

\section{Caseloads of SLTs for Learners with LLD with WFDs}

It is difficult to account for the low caseload of leamers with LLD and WFDs reported by the participants. Compared to the prevalence figure of $49 \%$ of all grade four and five leamers with LD having WFDs (German, 1998 cited by German, 2005), this low caseload of less than ten leamers with LLD and WFDs is of concern. As WFDs are the domain of the SLT, this may imply that the WFDs of some learners are not being identified. If the WFDs of learners in remedial schools which focus on reducing barriers to learning (Schoeman, 2003), and aim to return learners to mainstream schools, are not being identified and treated, these learners are possibly not receiving the help that they need.

Other possible reasons for this low caseload of learners with WFDs receiving intervention from SLTs may be low prioritisation given to WFDs in comparison to other difficulties experienced by learners in remedial schools. Furthermore, limited availability of procedures appropriate to the South African context may be another reason for small caseloads of learners with WFDs for SLTs in remedial schools.

\section{Limitations of the Study}

A number of limitations in both the implementation and results of this study are noted. Since the sample was limited to SLTs in South African remedial schools, the results obtained provide information specific to this population. This means that the findings cannot be generalised to other populations of SLTs.

The focus group discussion was only completed in KZN for logistical reasons. If these focus group discussions had been extended to other regions, the results may have provided a valuable comparison of findings. Some responses on the focus group discussion differed from the findings of the questionnaire, possibly because participants were given more opportunity' to explain or expand on certain issues.

The questionnaire used a predominantly close-ended question format with SLTs ticking the appropriate response. Such a format was selected to facilitate quick completion of: the questionnaire (Bailey, 1991). However, in selecting such a questionnaire format, more detailed responses were limited to questions posed in the focus group discussion. This may have had an impact on the quality of the information obtained.

It is recommended that biased or leading questions be avoided (Leedy, 1997). Although this was a criterion used for developing the questionnaire for this study, examples of tests were provided for specific questions. Generally the responses to those specific questions used the examples provided. Richer information may have been obtained with open-ended questions.

\section{CONCLUSION}

From this study, the following conclusions can be drawn. In terms of assessment of WFDs in South African remedial schools, there were concerns, strengths and opportunities for change. It seems that the vast majority of participant SLTs in South African remedial schools who typically assess WFDs use 
standardised tests. This is despite the tests being biased against our population and limited in their application for comprehensive assessment of WFDs in learners with LLDs. Reasons for this concerning assessment practice may include limited training in WFDs and limited resources. It is however encouraging that some participant SLTs in remedial schools were incorporating informal assessment measures into their standard test battery. Using informal strategies reduces test bias but the manner of obtaining the language sample and the mother tongue of the learner are crucial considerations. Using LSA, for example, is a useful strategy to observe WFDs in discourse, but LSA used with another tool such as the RWFS is not enough. Furthermore, SLTs need to include teachers in the assessment of WFDs. Teachers can provide information about the impact of WFDs on classroom performance. As SLTs follow policy changes in education and shift from standardised testing to criterion-referenced and educatorproduced tests (Department of Education Directorate: Inclusive Education, 2002), assessment practices for WFDs will become more applicable to our context.

In terms of intervention for WFDs by SLTs in South African remedial schools, there were also concerns, strengths and opportunities for change. Of concern was the finding that, consistent with Haynes (1993), some participant SLTs were only providing strategies for WFDs. While this is an important intervention principle, it is not sufficient (German, 1989a, German, 1992, Wiig \& Semel, 1984, Wolf \& Bowers, 2000). It seems that current service delivery models typify a "pull out" model with limited collaboration with teachers. This is problematic in that it is not in line with changes in educational policy. Other concerns include small caseloads for WFDs in learners with LLD and the language of instruction differing from the mother tongue of the learner receiving intervention. The predominant use of informal programmes in intervention for WFDs may be an advantage in that SLTs can plan and develop appropriate interventions for the South African context. Again, in the context of changing educational policy, an opportunity exists for reviewing and extending current intervention practices for WFDs.

With the changing education system for learners in remedial schooling, SLTs face many challenges. One of these is to revisit the management of WFDs in learners with LLD. SLTs in remedial education should embrace the challenges by reviewing and improving existing management practices. They should be encouraged to build on existing strengths to serve the learners with LLD whom they serve.

\section{ACKNOWLEDGEMENTS}

This article embodies the culmination of a thesis submitted to the University of KwaZulu- ${ }^{2}$ Natal by the first author, in partial fulfilment of the requirements for the degree, Master of Communication Pathology (Speech-Language Pathology), under supervision of the second and third authors.

\section{REFERENCES}

Apel, K. (2001). Developing evidence based practices and research collaborations in school settings. Language Speech and Hearing Services in Schools, 32, 149-152 (Prologue).

Apel, K. (1999). Checks and balances: Keeping the science in our profession. Language Speech and Hearing Services in Schools, 30 , 98-107.

2 The University of Durban-Westville and the University of Natal merged in 2004 to become The University of KwaZulu-Natal
Bailey, D.M. (1991). Research for the health professional: A practical guide $\left(2^{\text {nd }}\right.$ ed.). Philadelphia: F.A. Davis Company.

Baum, H.M. (1998). Overview, definitions, and goals for Asha's treatment outcomes and clinical trials activities. (What difference do outcome data make to you?). Language Speech and Hearing Services in Schools, 29, 246-249.

Bowling, A. (1997). Research methods in health: Investigating health and health services. Buckingham: Open University Press.

Casby, M.W. (1992). An intervention approach for naming problems in children. American Journal of Speech Language Pathology, 1, $35-42$.

Chiat, S., \& Hunt, J. (1993). Connections between phonology and semantics: An exploration of lexical processing in a language impaired child. Child Language Teaching and Therapy, 9, 200-213.

Department of Education Directorate: Inclusive Education. (2002). Draft guidelines for the implementation of inclusive education. Pretoria: South African Department of Education.

Department of Education. (2001). Education white paper 6. Special needs education: Building an inclusive education and training system. Pretoria: South African Department of Education.

Dockrell, J.E., Messer, D., George, R., \& Wilson, G. (1998). Children with word-finding difficulties-prevalence, presentation and naming problems. International Journal of Language and Communication Disorders, 33 (44), 445-454.

Easton, E., Sheach, S. \& Easton, S. (1997). Teaching vocabulary to children with wordfinding difficulties using a combined semantic and phonological approach: An efficacy study. Child Language Therapy and Teaching, 13 (1), 125-142.

Faust, M., Dimitrovsky, L., \& Shacht, T. (2003). Naming difficulties in children with dyslexia: Application of the tip-of-the-tongue paradigm. Journal of Leaming Disabilities, 36 (3), 203-215.

German, D.J. (1989a). A diagnostic model and a test to assess wordfinding skills in children. British Journal of Disorders of Communication, 24, 21-39.

German, D.J. (1989b). Test of Word Finding. USA: The Riverside Publishing Company.

German, D.J. (1992). Word finding intervention for children and adolescents. Topics in Language Disorders. 13 (1), 33-50.

German, D.J. (2005) Word finding difficulties. Retrieved October 1, 2003 and

September 27, 2006, from http://www.wordfinding.com/who.html

German, D.J., \& Simon, E. (1991). Analysis of children's word-finding skills in discourse. Journal of Speech and Hearing Research, 34, 309-316.

Haynes, C. (1993). Special issue on word finding, working memory, and reading in language impaired-children. Child Language Teaching and Therapy, 9 (3), 185-186.

Leedy, P. (1997). Practical research. (6 ${ }^{\text {th }}$ ed.). New York: Macmillan Publishers.

Lerner, J. (2000). Learning disabilities: Theories, diagnosis, and teaching strategies ( $8^{\text {th }}$ ed.). Boston: Houghton Mifflin.

McMillan, J.H., \& Schumacher, S. (2000). Research in education. A conceptual introduction. New York: Longman, Inc.

Miller, N. (1984). Some observations concerning formal tests in crosscultural settings. In: N. Miller (Ed.). Bilingualism and Disability. Assessment and Remediation. 107-114. San Diego: College-Hill Press, Inc. 
Nippold, M.A. (1992). The nature of normal and disordered word finding in children and adolescents. Topics in Language Disorders, $13(1), 1-14$.

Owens, R. (2004). Language disorders: A functional approach to assessment and intervention. London: Pearson Education lnc.

Pahl, J. \& Kara, M. (1992). The Renfrew Word Finding Scale: Application to the South African context. The South African Journal of Communication Disorders, 39, 69-74.

Renfrew, C.E. (1972). Word Finding Vocabulary Scale ( $2^{\text {nd }}$ ed.). Oxford: C. E. Renfrew

Renfrew, C.E. (1995). Word Finding Vocabulary Test. Bicester, Oxon: Speechmark, U. K..

Royal College of Speech Therapists (1998). Clinical guidelines by consensus for speech and language therapists. United Kingdom: Royal College of Speech Therapists.

Schoeman, M. (September, 2003). Changing roles of therapists in an inclusive education and training system. Unpublished workshop presented at Livingstone Primary School, Durban.

Semel, E., Wiig, E., \& Secord, W. (2003). Clinical Evaluation of Language Fundamentals-Four. San Antonio, TX: The Psychological Corporation.

Statistical Package for the Social Sciences Inc. (1995). Statistical Package for the Social Sciences. Chicago, Illinois: SPSS Inc.

Stiegler, L.N., \& Hoffman, P.R. (2001). Discourse-based intervention for word finding in children. International Journal of Communication Disorders, 34, 277-303.
Stockman, 1. (2000). The new Peabody Picture Vocabulary test-111: An illusion of unbiased assessment? Language, Speech, and Hearing Services in Schools, 31, 340-353.

Terrell, S., \& Terrell, F. (1993). African American cultures. In D. Battle. Communication disorders in multicultural populations (chapter one). Boston: Andover Medical Publishers.

Vithal, R., \& Jansen, J. (1997). Designing your first research proposal. Kenwyn, South Africa: Juta \& Co.

Webster, P.E. (1994). Linguistic factors in reading disability: A model for assessing children who are without overt language impairment. Child Language Teaching and Therapy, 10 (1), 259-281.

Wiig, E., \& Semel, E. (1984). Language assessment and intervention for the language learning disabled. (2nd ed.). Columbus: Charles $\mathrm{E}$. Merrill Publishing Company.

Wing, C.S. (1990). A preliminary investigation of generalisation to untrained words following two treatments of children's wordfinding problems. Language Speech and Hearing Services in Schools, (21) 151-156.

Wittmann, S. (1996). A case study in word finding. Child Language Teaching and Therapy, 12 (3), 300-311.

Wolf, M., \& Bowers, P.G., (2000). Naming speed processes and developmental reading disabilities. An introduction to the special issue of the double deficit hypothesis. Journal of Learning Disabilities, 33 (4), 322-324.

Wolf, M., \& Segal, D. (!992). Word finding and reading in the developmental dyslexias. Topics in Language Disorders, 51-23. 


\section{APPENDIX A}

\section{Questionnaire for Speech-Language Therapists (SLTs)}

to Investigate Practice with Word Finding Difficulties in Children with Language Learning Disabilities.

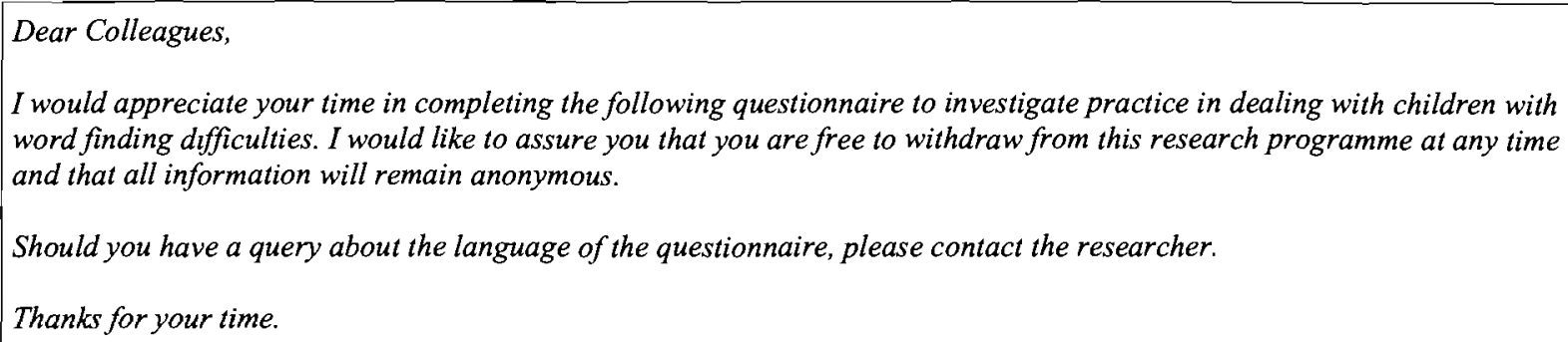

\section{SECTION A - TICK the appropriate box.}

1. How many years is it since you graduated as a SLT

\begin{tabular}{|l|l|l|}
\hline 1 & $1-5$ years & \\
\hline 2 & $6-10$ years & \\
\hline 3 & $11-15$ years & \\
\hline 4 & $16-20$ years & \\
\hline 5 & $21+$ years & \\
\hline
\end{tabular}

2. Which University did you attend?

\begin{tabular}{|l|l|l|}
\hline 1 & University of *Durban-Westville & \\
\hline 2 & University of the Witwatersrand & \\
\hline 3 & University of Pretoria & \\
\hline 4 & University of Cape Town & \\
\hline 5 & University of Stellenbosch & \\
\hline 6 & Other & \\
\hline
\end{tabular}

* The University of Durban-Westville and the University of Natal merged in 2004 to become The University of KwaZulu-Natal If other, please specify:

3. How many years have you been in practice as a SLT?

\begin{tabular}{|l|l|l|}
\hline 1 & $1-5$ years & \\
\hline 2 & $6-10$ years & \\
\hline 3 & $11-15$ years & \\
\hline 4 & $16-20$ years & \\
\hline 5 & $21+$ years & \\
\hline
\end{tabular}

4. What is (are) the language (s) of instruction at your school?

\begin{tabular}{|l|l|l|}
\hline 1 & English & \\
\hline 2 & Afrikaans & \\
\hline 3 & IsiZulu & \\
\hline 4 & IsiXhosa & \\
\hline 5 & SeTswana & \\
\hline 6 & TshiVenda & \\
\hline
\end{tabular}

\begin{tabular}{|l|l|l|}
\hline 7 & XiTsonga & \\
\hline 8 & IsiShangaan & \\
\hline 9 & IsiNdebele & \\
\hline 10 & SePedi & \\
\hline 11 & SiSwati & \\
\hline 12 & Other & \\
\hline
\end{tabular}

If other, please specify: 
5. During your training did you specifically cover word-finding difficulties as a topic in your course on learning disabilities?

\begin{tabular}{|l|l|}
\hline YES & \\
\hline NO & \\
\hline
\end{tabular}

6. How many years have you worked specifically with language learning disabled children with word finding difficulties?

\begin{tabular}{|l|l|l|}
\hline 1 & Never & \\
\hline 2 & $1-5$ years & \\
\hline 3 & $6-10$ years & \\
\hline 4 & $11-15$ years & \\
\hline 5 & $16-20$ years & \\
\hline 6 & $21+$ years & \\
\hline
\end{tabular}

7. If you responded never for question 6, please give a reason

\begin{tabular}{|l|l|l|}
\hline 1 & Lack of skill in the area of word finding therapy & \\
\hline 2 & Lack of awareness of the presence of word finding difficulties & \\
\hline 3 & $\begin{array}{l}\text { Limited assessment tools for the identification of word finding difficulties } \\
\text { Limited therapy programmes for word finding therapy }\end{array}$ & \\
\hline 5 & Low prioritisation in terms of intervention for word finding difficulties & \\
\hline 6 & Other & \\
\hline
\end{tabular}

If other, please specify:

8. What language (s) do you provide therapy for word finding difficulties in?

\begin{tabular}{|l|l|l|}
\hline 1 & English & \\
\hline 2 & Afrikaans & \\
\hline 3 & IsiZulu & \\
\hline 4 & IsiXhosa & \\
\hline 5 & SeTswana & \\
\hline 6 & TshiVenda & \\
\hline
\end{tabular}

\begin{tabular}{|l|l|l|}
\hline 7 & XiTsonga & \\
\hline 8 & IsiShangaan & \\
\hline 9 & IsiNdebele & \\
\hline 10 & SePedi & \\
\hline 11 & SiSwati & \\
\hline 12 & Other & \\
\hline
\end{tabular}

If other, please specify:

\section{SECTION B}

The following section need only be completed if you presently manage word-finding difficulties in children with language learning disabilities. TICK the appropriate box(es)

9. Who refers language learning disabled children to you?

\begin{tabular}{|l|l|l|l|l|l|}
\hline & $-\begin{array}{c}\text { Most } \\
\text { Referrals }\end{array}$ & Some & Few & None \\
\hline 1 & Psychologists & & & & \\
\hline 2 & SLTs & & & & \\
\hline 3 & Occupational Therapists & & & & \\
\hline 4 & Remedial Teachers & & & & \\
\hline 5 & Other & & & & \\
\hline
\end{tabular}

If other, please specify: 
10. How do you administer therapy to language learning disabled children with word finding difficulties?

\begin{tabular}{|l|l|l|l|l|l|}
\hline & & Always & Usually & Sometimes & Never \\
\hline 1 & Individual therapy only & & & & \\
\hline 2 & Group therapy & & & & \\
\hline 3 & Both & & & & \\
\hline
\end{tabular}

11. How many language learning disabled children with word finding problems do you see per week?

\begin{tabular}{|l|l|l|}
\hline 1 & None per week & \\
\hline 2 & $1-5$ years & \\
\hline 3 & $6-10$ years & \\
\hline 4 & $11-15$ years & \\
\hline 5 & $16-20$ years & \\
\hline 6 & $21+$ years & \\
\hline
\end{tabular}

12. How many children are there in your caseload for whom the language of instruction is different to their mother tongue?

\begin{tabular}{|l|l|l|}
\hline 1 & None & \\
\hline 2 & $1-5$ years & \\
\hline 3 & $6-10$ years & \\
\hline 4 & $11-15$ years & \\
\hline 5 & $16-20$ years & \\
\hline 6 & $21+$ years & \\
\hline
\end{tabular}

13. What assessment measures do you use?

\begin{tabular}{|l|l|l|l|l|l|}
\hline & & Always & Usually & Sometimes & Never \\
\hline 1 & Standardised tests & & & & \\
\hline 2 & Informal & & & & \\
\hline 3 & Other & & & & \\
\hline
\end{tabular}

If other, please specify:

14. Please list the standardised tests you use to identify word finding difficulties in language learning disabled children. Please list in order of frequency of use e.g. 3. Renfrew Word Finding Scale.

\begin{tabular}{|c|c|}
\hline Most frequently used & \\
\hline 1 & \\
\hline 2 & \\
\hline 3 & \\
\hline 4 & \\
\hline 5 & \\
\hline 6 & \\
\hline
\end{tabular}


15. Please list the informal measures you use to identify word finding difficulties in language learning disabled children.

Please list in order of frequency of use, e.g. 1. Language sample analysis.

\begin{tabular}{|c|c|}
\hline Most frequently used & \\
\hline 1 & \\
\hline 2 & \\
\hline 3 & \\
\hline 4 & \\
\hline 5 & \\
\hline 6 & \\
\hline
\end{tabular}

16. What formal programmes/ and or activities do you use in your work with word finding difficulties in language learning disabled children. Please list in order of frequency of use e.g. 4. Lingui Systems Auditory Association Activity Booklet.

\begin{tabular}{|c|c|}
\hline Most frequently used & Name of Programme or Activities Used \\
\hline 1 & \\
\hline 2 & \\
\hline 3 & \\
\hline 4 & \\
\hline 5 & \\
\hline
\end{tabular}

17. what therapeutic strategies do you use in your work in language learning disabled children with word finding difficulties? E.g. 5. Phonetic cueing. Please list in order of frequency.

\begin{tabular}{|c|c|}
\hline Most frequently used & Name of Therapeutic Strategy Used \\
\hline 1 & \\
\hline 2 & \\
\hline 3 & \\
\hline 5 & \\
\hline 6 & \\
\hline
\end{tabular}

18. What role do other team members play in your management of word finding difficulties in the language learning disabled children that you treat?

\begin{tabular}{|c|c|c|c|c|c|c|}
\hline & & Always & Mostly & $\begin{array}{l}\text { Some- } \\
\text { times }\end{array}$ & $\begin{array}{c}\text { Hardly } \\
\text { ever }\end{array}$ & Never \\
\hline 1 & $\begin{array}{l}\text { Teachers are involved in the management } \\
\text { process by observing SLT classroom based } \\
\text { therapy to gain insight into strategies used. }\end{array}$ & & & & & \\
\hline 2 & $\begin{array}{l}\text { Teachers are involved in the management } \\
\text { process by providing strategies for word } \\
\text { finding difficulties in the classroom }\end{array}$ & & & & & \\
\hline 3 & $\begin{array}{l}\text { Occupational therapists are involved in the } \\
\text { management process by providing strategies } \\
\text { for word finding difficulties in their interac- } \\
\text { tions during their therapy sessions }\end{array}$ & & & & & \\
\hline 4 & $\begin{array}{l}\text { Psychologists are involved in the manage- } \\
\text { ment process by providing strategies for } \\
\text { word finding difficulties in their interactions } \\
\text { during their therapy sessions }\end{array}$ & & & & $\therefore$ & \\
\hline 5 & $\begin{array}{l}\text { Staff are aware of the impact of WFD on } \\
\text { their assessment. }\end{array}$ & & & & & \\
\hline
\end{tabular}




\section{SECTION C - TICK the appropriate box.}

19. Do you feel that your therapy for word finding difficulties in language learning disabled children is effective?

\begin{tabular}{|c|c|c|c|}
\hline Always & Usually & Sometimes & Never \\
\hline & & & \\
\hline
\end{tabular}

20. How do you measure the effectiveness of your therapy?

\begin{tabular}{|c|c|c|c|c|c|}
\hline & $\begin{array}{c}\text { Strongly } \\
\text { agree }\end{array}$ & Agree & Neutral & $\begin{array}{l}\text { Dis- } \\
\text { agree }\end{array}$ & $\begin{array}{l}\text { Strongly } \\
\text { disagree }\end{array}$ \\
\hline \multicolumn{6}{|l|}{$\begin{array}{l}\text { I feel my therapy for word finding difficulties in children } \\
\text { with language learning disabilities is effective }\end{array}$} \\
\hline \multicolumn{6}{|l|}{$\begin{array}{l}\text { I feel the effectiveness of my therapy is based on my theoreti- } \\
\text { cal knowledge related to word finding difficulties in language } \\
\text { learning disabled children }\end{array}$} \\
\hline \multicolumn{6}{|l|}{$\begin{array}{l}\text { There is a strong degree of carry-over of skills developed } \\
\text { during therapy for word finding difficulties in children with } \\
\text { language learning disabilities in terms of accuracy, fluency } \\
\text { and word retrieval }\end{array}$} \\
\hline \multicolumn{6}{|l|}{$\begin{array}{l}\text { There is a strong degree of carry-over of skills developed } \\
\text { during therapy for word finding difficulties in children with } \\
\text { language learning disabilities in terms of an increase in read- } \\
\text { ing fluency }\end{array}$} \\
\hline \multicolumn{6}{|l|}{$\begin{array}{l}\text { I feel the effectiveness of my therapy is based on the assess- } \\
\text { ment measures I use to identify word finding difficulties in } \\
\text { children with language learning disabilities }\end{array}$} \\
\hline \multicolumn{6}{|l|}{$\begin{array}{l}\text { I use assessments or re-assessments to measure therapy out- } \\
\text { comes for word finding difficulties in children with language } \\
\text { learning disabilities }\end{array}$} \\
\hline \multicolumn{6}{|l|}{$\begin{array}{l}\text { I use teacher checklists to measure the effectiveness of my } \\
\text { therapy for word finding difficulties in children with lan- } \\
\text { guage learning disabilities }\end{array}$} \\
\hline $\begin{array}{l}\text { I use parent checklists to measure the effectiveness of my } \\
\text { therapy for word finding difficulties in children with lan- } \\
\text { guage learning disabilities }\end{array}$ & & & & & \\
\hline
\end{tabular}

21. What is your opinion on the management procedures used for word finding difficulties in children with language learning disabilities?

\begin{tabular}{|c|c|c|c|c|c|}
\hline$i \ldots$ & $\begin{array}{l}\text { Strongly } \\
\text { agree }\end{array}$ & Agree & Neutral & Disagree & $\begin{array}{c}\text { Strongl } \\
\text { y dis- } \\
\text { agree }\end{array}$ \\
\hline $\begin{array}{l}\text { Assessment procedures are relevant to the South African } \\
\text { Context }\end{array}$ & & & & & \\
\hline $\begin{array}{l}\text { Assessment procedures are useful in identifying such } \\
\text { difficulties }\end{array}$ & & & & & \\
\hline $\begin{array}{l}\text { Assessment procedures provide sufficient detail to facili- } \\
\text { tate the formulation of treatment goals }\end{array}$ & & & & & \\
\hline $\begin{array}{l}\text { Intervention procedures are relevant to the South African } \\
\text { Context }\end{array}$ & & & & & \\
\hline $\begin{array}{l}\text { Intervention procedures are useful in addressing word } \\
\text { finding difficulties }\end{array}$ & & & & & \\
\hline $\begin{array}{l}\text { Therapy outcome measures are useful in identifying the } \\
\text { benefit of therapy }\end{array}$ & & & & & \\
\hline
\end{tabular}


22. Did your training prepare you to adequately manage language learning disabled children with word finding difficulties?

\begin{tabular}{|l|l|l|l|l|l|}
\hline & $\begin{array}{c}\text { Strongly } \\
\text { agree }\end{array}$ & Agree & Neutral & Disagree & $\begin{array}{c}\text { Strongl } \\
\text { y dis- } \\
\text { agree }\end{array}$ \\
\hline $\begin{array}{l}\text { My training in word finding difficulties in language } \\
\text { learning disabled children was indepth and relevant }\end{array}$ & & & & & \\
\hline $\begin{array}{l}\text { My training in word finding difficulties in language } \\
\text { learning disabled children was limited }\end{array}$ & & & & & \\
\hline $\begin{array}{l}\text { My training in word finding difficulties in language } \\
\text { learning disabled children focused on theory }\end{array}$ & & & & & \\
\hline $\begin{array}{l}\text { My training in word finding difficulties in language } \\
\text { learning disabled children focused on clinical experi- } \\
\text { ence }\end{array}$ & & & & & \\
\hline $\begin{array}{l}\text { My training in word finding difficulties in language } \\
\text { learning disabled children was a balance of theory and } \\
\text { clinical experience }\end{array}$ & & & & & \\
\hline $\begin{array}{l}\text { My training in word finding difficulties in language } \\
\text { learning disabled children adequately prepared me for } \\
\text { practice in this area }\end{array}$ & & & & & \\
\hline
\end{tabular}

\section{Is word finding an area that you would like to be addressed for Continuing Professional Development?}

\begin{tabular}{|l|l|}
\hline YES & \\
\hline NO & \\
\hline
\end{tabular}




\section{APPENDIX B}

\section{Focus Group Discussion Interview Schedule}

Thank you for participating today. My role is as facilitator to discuss some of the responses to the questionnaires on practice for WFDs. The discussion is informal. Based on the responses obtained, I would like to explore a few issues. It is important for me to briefly discuss some of the reasons why I selected WFDs as a topic to research:

- It has always been a significant part of my caseload within a remedial school environment

- I have not always been sure which assessments, interventions, strategies or therapy outcome measures to use when dealing with WFDs and have sometimes experienced frustration at the benefit of intervention

- With the proposed changes for service delivery in education, I have queries about how practice for WFDs will be affected

100 questionnaires were sent to remedial schools in South Africa. 73 were returned and 69 were used for analysis. (Four were not analysed as the therapists did not work with WFDs or had no experience in the area).

1. I would like to start by asking how you define WFDs? (Depending on responses, use this as adjusted probe question: Do you for example consider it to be a processing deficit or a storage deficit?

2. In terms of caseload, it was found that all of you provide therapy for WFDs in English. Some of the children with WFDs in your caseloads speak English as a second language. What impact does this have on your assessment and intervention. What patterns do you encounter, if any?

3. In terms of formal assessments, the RWFS was by far the most frequently used tool for identifying WFDs. How do you feel about the use of the RWFS? What do you feel about its "fit" to your definition of WFDs? How do you feel about its appropriacy and effectiveness in the assessment of WFDs?

4. Differences were noted in terms of practice specifically regarding individual versus group therapy. Based on your experience in schools, what information can you provide about this pattern?

5. Do you find intervention needs change from year to year? Can you explain this?

6. Within a school, the various SLTs differed as to whether they used standardised versus informal assessment procedures and in their assessment and treatment approaches. Can you provide possible reasons for this?

7. Participants frequently responded that their undergraduate training in WFDs was inadequate but generally therapists said WF therapy is sometimes or usually effective. Why do you think this is?

8. Every participant said "Yes" to WF being a topic of interest for CPD. Why is this? What other solutions for increasing knowledge in this area do you have? Who would you like to see doing a WFD workshop and how do you think it could be done to be of most value to you?

9. Many therapists seemed to have a small caseload for WFDs and some gave it low priority in terms of intervention. How significant do you think the impact of WFDs is on academic performance?

10. How do you see WF therapy fitting into the proposed changes in education such as an increased role for the therapist as consultant and less role in providing intervention to children?

11. Are there any other issues you would like to raise? 


\section{NATURE OF PUBLICATION}

The South African Journal of Communication Disorders publishes reports and papers concerned with research, and critically evaluative theoretical and philosophical conceptual issues dealing with aspects of human communication and its disorders, dysphagia, service provision, training and policy. The Journal will accept the following three types of articles:

- Research articles defined as reports based on qualitative or quantitative research.

- Original general articles which are reports of work usually, but not exclusively, theoretical in nature and regarded as providing a significant, critically evaluative contribution to the field of human communication and its disorders and/or dysphagia.

- Review articles which are usually written by authors invited by the Journal's editorial team to comment, express opinions and or critically evaluate a topic.

The Journal will not accept material which has been published elsewhere or that is currently under review by other publications.

\section{MANUSCRIPT SUBMISSION \& STYLE REQUIREMENTS}

- All articles may only be submitted electronically using the online manuscript submission, review and tracking system via the following website: www.saslha.co.za.

- MS Word must be used for the text. MS Word or MS PowerPoint should be used for figures, and MS Excel for tables.

- Authors' FULL addresses, telephone and fax numbers and email address must be provided via the online system. DO NOT include any personal details (name, affiliation) in the manuscript to ensure a double-blinded review process.

- Articles must be in double spacing and in a font size of 12 .

- Filenames must include the first author's initials and a clearly identifiable key word.

- Articles must not exceed 30 pages.

- The order of the manuscript should be: title page, abstract and key words, text, references, tables, legends, and figures.

- The title page must only contain the titie of the article without any author details.

Each article must contain an English abstract of no more than 200 words with 5-7 key words.

Strict adherence to the Publication Manual of the American Psychological Association ( $5^{\text {th }}$ ed., 2001) is required.

Headings are NOT NUMBERED. The order of importance is indicated as follows:

- Main heading in capitals and bold print.

- Sub-headings in capitals, bold and italic print.

- Sub-subheadings in upper and lower case bold and italic print.

- Sub-sub-sub-heading in upper and lower case bold print.

Major headings, where applicable, must be in the order of INTRODUCTION, METHOD, RESULTS, DISCUSSION, CONCLUSION, ACKNOWLEDGEMENTS, and REFERENCES.

All paragraphs should be indented.

All tables, figures and illustrations must be numbered and provided with titles.

The title of tables, which appear above, and of figures, which appear below, must be concise but explanatory.

Allow for $50-75 \%$ reduction in printing of tables, figures and illustrations.

Each table, figure or illustration must appear on a SEPARATE page.

Do not include more than 10 tables, figures or illustrations.

Colour graphics are NOT preferred. If submitted, extra cost of colour reproduction and printing must be covered by the author prior to publication.

A short running title should be listed at the top left-hand corner of the title page. Any information about grants or other financial support should be supplied as an unnumbered footnote to the article title.

Graphics, audio and/or video files (not exceeding 2MB) may be submitted for the electronic online Journal. Consult the Editor in Chief regarding required file formats.

Authors must use gender-, race-, and creed-inclusive language. Authors must ensure adherence to national and/or international ethical codes.

British spelling (e.g. centralise not centralize, behaviour not behavior) is preferred.

\section{REFERENCING}

- References must be cited in the text by author's name and the date, e.g. Van Riper (1971).

- Where there are more than two authors, after the first occurrence, et al. may be used.

- The names of all authors must appear in the Reference List which must be listed in strict alphabetical order in triple spac. ing at the end of the article.

- All references must be included in the List, including secondary sources.

- Only acceptable abbreviations of journals may be used, (see DSI-1 ABSTRACTS, October; or The World List of Scientific Periodicals).

- Author(s) should use references that reflect an international diversity among authors of both source articles and cited articles.

- The number of references should not exceed 30, unless specifically warranted.

\section{Examples}

Locke, J.L. (1983). Clinical Psychology: The explanation and treatment of speech sound disorders. J. Speech Hear Disord., 48 339341.

Penrod, J.P. (1985). Speech discrimination testing. In J. Katz (Ed.), Handbook of clinical audiology ( $3^{\text {rd }}$ ed.). Baltimore: Williams \& Wilkins.

Davis, G. \& Wilcox, M.J. (1985). Adult aphasia rehabilitation: Applied pragmatics. San Diego, CA: College-Hill.

\section{EDITING}

- Articles must be corrected for grammar and style prior to submission.

- Only articles complying with the above requirements will be accepted for review.

\section{REVIEWING SYSTEM}

- The double-blind peer review system is employed as a method of quality control of this publication and ensures that author (s) and reviewers do not know each others' names.

- Each article is sent to two independent reviewers, selected according to their area of expertise, to assess the quality of the manuscript's scientific and technical content.

- Author(s) must ensure that the manuscript does not contain information/clues as to the identity of the author(s).

- The Editor in Chief retains the final responsibility for decisions regarding revision, acceptance or rejection of the manuscript. This process is usually done in consultation with the manuscript's editor and/or the editorial team, as necessary.

DEADLINE FOR CONTRIBUTIONS: $28^{\text {th }} / 29^{\text {th }}$ February each year

PUBlication FeE: Authors will be expected to pay a publication fee. The exact amount is determined by printing costs.

QUERIES AND CORRESPONDENCE: should be addressed to The Editor in Chief

South African Journal of Communication Disorders

South African Speech-Language-Hearing Association PO Box 5710

The Reeds

0158

South Africa

Email SASLHA at admin@saslha.co.za for the current Editor in Chief's email address.

Author's Responsibility: The South African Journal of Communication Disorders is not responsible for authors' views and does not endorse any of the products or materials advertised in the Journal.

Copyright: The copyright of all articles printed in The South African Journal of Communication Disorders is reserved by The South African Speech-Language-Hearing Association (SASLHA).

\section{Editorial Board}

Editor in Chief:

Editors:

Technical Editor:
Dr Mershen Pillay

Prof Harsha Kathard, Dr Elsie Naude and Prof Eleanor Ross

Ms Carmen Milton 